\title{
EFFECT OF ASCORBIC ACID INJECTION IN PRE-INCUBATED HY-LINE LAYER EGGS ON HATCHABILITY AND SOME BLOOD AND HEMATOLOGICAL PARAMETERS OF HATCHED CHICKS
}

\author{
A.M. Badran ${ }^{1}$; M. H. Hatab ${ }^{2}$ and N. S. Ibrahim ${ }^{2}$
}

${ }^{1}$ Anim. Prod. Res. Inst., Agric. Res. Center, Ministry of Agric. Dokki, Giza

${ }^{2}$ Biological Applications Dep., Nuclear Res. Center, Atomic Energy Authority, P.O. Box 13759, Egypt

Corresponding author:aamel555@gmail.com

Received: 12 / 10 /2017 Accepted: 01/11/2017

\begin{abstract}
The present work was carried out to study the effect of ascorbic acid (AsA) injection into fertile Hy-line layer eggs on hatchability, mortality and some blood and hematological parameters of hatched chicks. Three hundred Hy-line layer eggs were divided into four equal groups with 75 eggs for each group with three replicate (25 fertile eggs for each replicate). The first group was injected, pre-incubation, in the air cell by $50 \mu 1$ deionized water and served as a sham control. While the second, third and fourth groups were injected in the air cell with either 2, 4 or $6 \%$ ascorbic acid. dissolved in $50 \mu \mathrm{l}$ deionized water and served as AsA-treated groups.

Eggs were incubated at $37.5^{\circ} \mathrm{C}$ and $60 \%$ relative humidity during the first $19^{\text {th }}$ days of incubation. Eggs were turned automatically every 2 hour until the $19^{\text {th }}$ day. At the $10^{\text {th }}$ day of incubation, eggs were examined by light candling to remove infertile eggs . All eggs were transferred to the hatchery at the end of the $19^{\text {th }}$ day of incubation, and placed in hatching trays at $37^{\circ} \mathrm{C}$ temperature and $70-75 \%$ relative humidity until hatching.

hatchability rate, hatching and hatched chick's body weight unlike mortality were significantly higher in the $6 \%$ AsA groups than all the AsA groups or the control group. Hemoglobin concentration was significantly $(\mathrm{p}<0.05)$ higher in the the $4 \%$ AsA group and the $6 \%$ AsA group $(\mathrm{p}<0.05)$ as compared to the $2 \%$ AsA or control groups. However there was no significant difference in the cholesterol concentration between the control group and all the AsA groups. Glucose and triiodothyronin concentrations were significantly $(\mathrm{p}<0.05)$ higher in the $6 \%$ AsA group than the $2 \%$ AsA or control groups. In conclusion, our study suggests injecting 50 microliters of $6 \%$ ascorbic acid reduced embryonic mortality and improvd hatchability and hatched chicks'body weight.
\end{abstract}

Key words: In-ovo injection, ascorbic acid, hatchability, embryo mortalities, blood parameters 
Badran, A.M. ${ }^{1}$ et al.

\section{INTRODUCTION}

The subsequent development of avian embryos and hatched chicks are influenced by the yolk nutrient status (AlMurrani, 1982). Many nutrients have important structural, physiological, and immunological roles in avian embryogenesis and growth performance. In-ovo injection of nutrients may help overcome any constraint of inadequate egg nutrition. During early development, there is rapid oxidative metabolism that leads to the production of large quantities of free radicals in many tissues, making them more susceptible to oxidative damage. Antioxidants are a critical defense against these free radicals. The developing embryo may use antioxidants found in the yolk in order to reduce the impact of free radicals. There are several reports regarding the effect of ascorbic acid (AsA, vitamin C) as an anti-stress agent on productive performance parameters in birds such as growth and reproductive traits, the most important of them are fertility and hatchability. In incubated eggs, chick embryos may be subjected to stress caused by excessive production of metabolic heat during the latter part of egg incubation so, the addition of vitamin $\mathrm{C}$ as an anti-stress agent may be beneficial for embryos viability and to protect them from any stress during incubation (Tullett, 1990).

Also, the in-ovo injection of nutrients may be used to improve hatchability and hatchling quality (Ohta et al., 2001). For instance, the injection of vitamins in ovo has been applied to improve hatchability and hatchling body weight (Robel and Christensen, 1991 and Robel, 1993). Nowaczewski et al. (2012) reported that, when eggs are incubated under normal conditions, ascorbic acid has shown, dose-dependent, positive effects on hatchability and hatchlings body weight. Zakaria et al. (1998) reported that vitamin $\mathrm{C}$ injected into chicken eggs was demonstrated to have a favourable impact on hatchability results, embryo weight at different incubation days and, consequently, on chick body weight after hatching as well as on the reduction of embryo death during incubation.

In addition, the use of ascorbic acid as a nutritional additive supplement during the fetal stage has shown dose-dependent positive effects of this vitamin on hatchability and body weight at hatching (Ghonim et al., 2009; Mohammed et al., 2011 and Nowaczewski et al., 2012). Ascorbic acid has been demonstrated to improve immunoresponsiveness and increase disease resistance in poultry by optimizing the immune system (Pardue and thaxton, 1986 and Rund, 1989).

There is no data in the literature on the effects of pre-incubation in-ovo injection of vitamin $\mathrm{C}$ on incubation and hematological parameters of chicks hatched from eggs incubated under thermoneutral conditions. Therefore, the present study examined the effects of preincubation in-ovo injection of ascorbic acid (AsA) on hatchability and some blood and hematological parameters of the hatched chicks.

\section{MATERIALS AND METHODS}

The present work was carried out at the poultry research unit, Biological Applications Department, Nuclear Research Center, Egyptian Atomic Energy Authority. The effect of preincubation in-ovo injection of ascorbic acid (AsA) on hatchability and some hematological parameters of the hatching chicks was studied. Three hundred Hyline layer eggs were cleaned with ethanol pre- incubation, then individually weighed $(65 \pm 2 \mathrm{~g})$ and divided into four 
In-ovo injection, ascorbic acid, hatchability, embryo mortalities, blood parameters

equal groups with 75 eggs for each group with three replicate ( 25 fertile eggs for each replicate). The first group was injected in the air cell by $50 \mu$ l deionized water and served as a sham control. While the second, third and fourth groups were injected in the air cell with either 2 , 4 or $6 \%$ ascorbic acid (AsA) dissolved in $50 \mu \mathrm{l}$ deionized water and served as AsAtreated groups.

Eggs were incubated at $37.5^{\circ} \mathrm{C}$ and $60 \%$ relative humidity during the first 19 days of incubation. Eggs were turned automatically every 2 hour until the $19^{\text {th }}$ day. At The $10^{\text {th }}$ day of incubation, eggs were examined by light candling to remove infertile eggs. All eggs were transferred to the hatchery at the end of the $19^{\text {th }}$ day of incubation, and placed in hatching trays at $37^{\circ} \mathrm{C}$ temperature and $70-75 \%$ relative humidity until hatching. Hatchability (number of hatched chicks / number of total hatching eggs) and hatchability of the fertile eggs (number of hatched chicks / number of fertile eggs incubated), hatched chicks'body weight and embryonic mortalities were obtained. At hatch, blood samples were collected from fifteen chicks per group (five hatchlings per replicate) by decapitation. Blood samples were divided into two tubes, the first with anticoagulants to determine some blood hematological parameters such as hematocrit (HCT) (Harmon, 1936), hemoglobin (HGB) (Harmon, 1936), total red blood cells count (RBC) (Lucas and Jamroz, 1961) and mean corpuscular volume of erythrocytes (MCV). While the second tubs without anticoagulants and stored at normal room temperature for half an hour to allow clotting of the blood. Then the blood was centrifuged to separate the serum. Serum was then frozen and stored at $-20^{\circ} \mathrm{C}$ until assayed.

$\begin{array}{lll}\text { Serum glucose } & \text { and } & \text { cholesterol } \\ \text { concentrations } & \text { were } & \text { determined }\end{array}$

colorimetrically using a commercial kit produced by Stanbio Company, USA and measured on computerized spectrophotometer model Milton Roy Spectronic 1201 (1201 Ivyland Road Ivyland, PA 18974, United State). While, triiodothyronin $\left(\mathrm{T}_{3}\right)$ concentration was determined using radioimmuno assay (RIA) Kit bought from IZOTOP Company (INSTITUTE OF ISOTOPES Ltd.) (http://www.izotop.hu) and samples were counted on a Pacard Gamma Counter model 540501 RIA SAR.

\section{Statistical analysis}

One-way analysis of variance was used to determine the effect of ascorbic acid (AsA) injection in Hy-line layer eggs on hatchability and some blood parameters. Data were statistically analyzed by the General Liner Model Procedure of the SAS software (SAS Institute, 2002). Mean values were compared using Duncan's Multiple Range Test (Duncan, 1955) when significant differences at $(\mathrm{P}<$ 0.05 ) existed.

The model used was:

$\mathrm{Yi}=\mu+\mathrm{Ti}+\mathrm{Ej}$

Where:

$\mathrm{Yi}=$ any value from the overall

population.

$\mu=$ the overall mean.

$\mathrm{Ti}=$ the effect of the ${ }^{\mathrm{i}}$ th treatment $(\mathrm{i}=1$, control\& 2, AsA treatment).

$\mathrm{Ej}=$ the random error associated with the $\mathrm{j}_{\text {th individual. }}$

\section{RESULTS}

Table (1) shows The effect of preincubation in-ovo injection of ascorbic acid (AsA) on hatchability, hatchability of fertile eggs, embryonic mortalities percentage and hatched chicks' body weight. The data shows that hatchability and hatchability of fertile eggs were 
Badran, A.M. ${ }^{1}$ et al.

significantly higher $(\mathrm{p}<0.05)$ in the AsA groups than the control group and highly significantly increased in the $6 \%$ AsA group than the other AsA groups. While, mortality percentage was significantly decreased in the AsA groups than the control group and significantly lower in the $6 \%$ AsA group than the other AsA groups. Finally, hatched chicks' body weight was was significantly higher in the AsA $6 \%$ group than other AsA groups, while there were no significantly different between the control and the 2 or $4 \%$ AsA groups. The effect of pre-incubation inovo injection of ascorbic acid on some hematological parameters is shows in Table (2). Data shows that however hemoglobin concentration (HGB) was not significantly differ between the control group and the $2 \%$ AsA group, its concentration was significantly increased in the the $4 \%$ AA and highly significantly increased in the $6 \%$ AsA. While, hematocrit percentage (HCT \%), red blood cell counts (RBC) and mean corpuscular value (MCV) were not significantly different between the control and all the AsA groups. Table (3) shows the effect of pre-incubation in-ovo injection of ascorbic acid on serum cholesterol, glucose concentrations and triiodothyronin level. The data indicated that there was no significant difference in the cholesterol concentration between the control group and all the AA groups. However, glucose and triiodothyronin concentrations were significantly higher in the $6 \%$ AsA group than the $2 \%$ AsA group, there were no significantly differences between the control group and the $2 \%$ AsA group.

\section{DISCUSSION \\ Hatchability, mortality rates and hatched chicks'body weight:}

One of the basic biological functions of the egg shell for the domestic fowl is to allow for adequate movement of water vapor and respiratory gases. It consists of overlaying cuticle which is penetrated by thousands of microscopic pores which are essential for the exchange of respiratory gases during incubation (Tullett, 1978). It may also enhance or reduce the movement of water vapor across the shell (Meir and Nir, 1984). Ascorbic acid is a weak acid and the ability of diluted acid to interact with the eggshell cuticle was reported by Burley and Vadehra (1989). Egg injection or dipping with vitamins such as: pantothenic acid and AA has been applied during incubation to study their effects on hatchability of poultry eggs (Zakaria and El-Anezi, 1996 and Shafey, 2002). Hatchability improved by dipping or spraying of AA solutions (contains 10, 20, 30 and $40 \mathrm{gm}$. AsA/ liter distilled water) during the incubation period (Tag El-Din et al., 2004). Also, Awad and Abd Al-Haleem (2015) reported that hatchability (\%) was significantly improved by about 2.64, $3.87,8.77,2.65$ and $2.55 \%$ for eggs dipped into $5.0,10.0,15.0,20.0$ and $25.0 \mathrm{~g}$ AsA/ L solution as compared with those dipped into distilled water $(0.0 \mathrm{~g}$ AsA/L), respectively. Our results agreed with Ipek et al. (2004) and Nowaczewski et al. (2012), who observed improvement in hatchability of eggs with injection of 3 and $6 \mathrm{mg}$ of ascorbic acid. This fact shows that the effect of in-ovo vitamin $\mathrm{C}$ injection on the development of the embryo varies with solution concentration and the stage of embryo development in which the injection is performed. 
In-ovo injection, ascorbic acid, hatchability, embryo mortalities, blood parameters

Jochemsen and Jeurissen (2002) reported that the age at which the inoculation procedure is performed can affect the site where the product is applied. This improvement may be due to the decreasing of embryonic mortality where AsA as an anti-stress agent led to the reduction of corticosterone, which has a negative impact in collagen synthesis and the metabolism of minerals and vitamin D (Tullett, 1990; Kutlu, 2001; Lohakare et al., 2005 and Ghonim et al., 2008).

Hatchability percentage improved and embryonic mortality decreased by dipping eggs into AsA solution $10 \mathrm{~g} /$ liter for up to $2 \mathrm{~min}$ before incubation period (Shafey, 2002), and by dipping or spraying AsA solutions at the $14^{\text {th }}$ day of incubation (Ghonim et al., 2008). The improvement of hatchability may be due to the increase of embryonic viability, during the late part of incubation period, by the AsA dipping treatment which may act as a positive agent that led to the decrease of the excessive egg temperature as a result of intense fetal growth and increase metabolism (Shafey, 2002). Ohta et al. (1999) observed a reduction in hatchability after amino acid inoculation, in ovo, was performed before incubation. According to Ohta and Kidd (2001), product injection in ovo should be made either in the extra embryonic cavity or in the yolk sac to prevent hatching reduction; however, the authors injected at seven days of incubation and not preincubation as in the present study.

While, our results differ from those obtained by Pires et al. (2011), who observed an increase in hatching rate with injection of $1 \%$ ascorbic acid in ovo preincubation. Uni and Ferket (2003) reported that injecting high concentrations of the AsA may interfere with the osmotic balance and affect embryo development which indicates that the lower hatching rate was not due to the injected ascorbic acid changing the osmotic balance of the eggs excessively. Finally, Bhanja et al. (2007) studied the effect of in ovo injection of vitamins $C$ on the embryonic and post-hatch growth performance. On the $14^{\text {th }}$ day of incubation, five groups were injected with $50 \mathrm{mg}$ Vitamin-C dissolved in 0.5 $\mathrm{ml}$ of sterile water. They found that chick weight to egg weight ratio (\%) was higher $(\mathrm{P}<0.01)$ in chicks injected with Vitamin-C (72.26\%) than un- injected control $(70.94 \%)$. The higher in hatched chick'body weight my be due to increasing triiodothyronin hormone.

\section{Blood parameters:}

Hemoglobin (HGB) content values were significantly affected by the AsA injections. The results showed a linear effect on the levels of ascorbic acid in the solution injected in ovo prior to incubation. Our results were similar to Moura and Pedroso (2003) who reported that ascorbic acid is related to an increase of HGB values. Considering that hemoglobin is related to the transport of gases, these data suggest that increasing the concentration of the inoculated ascorbic acid solution increased respiratory rate, and consequently, the hematopoietic process and respiratory potential, without changing shell conductance. The increase of the HGB value might be associated with dehydration (Campbell, 1994). However, treatment did not affect either the weight of chicks at hatching or the presence of seemingly dehydrated chicks, thus ruling out this possibility. The other hematologic characteristics as hematocrit (HCT), red blood cells count (RBC), Mean corpuscular value (MCV) were not affected significantly $(p>0.05)$ by the 


\section{Badran, A.M. ${ }^{1}$ et al.}

treatments. These data are similar to those of Ghonim et al. (2009), who reported no effect of the injection of ascorbic acid on the erythrocyte of broiler chicks; however, the authors only looked at the effects of this vitamin in chicks resulting from eggs injected on the $14^{\text {th }}$ day of incubation. In addition, Sgavioli et al. (2013) reported that injecting fertile eggs with ascorbic acid did not significantly affect some blood hematological parameters as red blood cell (RBC's) count, HCT \%, MCV, or on serum glucose and triiodothyronin concentrations.

Although the egg is considered a functional food (Stadelman, 1999) and is an excellent source of protein, essential lipids, vitamins and minerals (Zeidler, 2002), many people reduce their consumption of eggs because they consider that high egg cholesterol content may cause cardiovascular diseases. Over the last three decades, many researchers have tried to reduce the egg cholesterol content by genetic selection, inclusion of drugs in the ration, or dietary manipulation of hens'diet (Shakeel, 2010). Many researches studied the effect of large doses of vitamin C (Ajakaiye et al., 2010; El-sheikh and Salama, 2010). However, the effect of vitamin $\mathrm{C}$ on yolk and serum cholesterol has not been established. Our results indicated that there were no significantly affect of inovo injection of ascorbic acid on serum cholesterol concentration. Our results are in agreement with Mohiti-Asli et al. (2007) who studied the effect of vit C (AsA) (200 mg / kg diet) on yolk and serum cholesterol. They found that there was no significant differences in serum and yolk cholesterol concentration between different experimental groups.

However, Sanda (2015) studied the effect of supplemention eighty (80) Isa brown layers of 28 weeks old with $0,100,150$ and $200 \mathrm{mg}$ vitamin $\mathrm{C}$ on yolk and serum cholesterol levels. They found that vitamin $\mathrm{C}$ reduced yolk and serum cholesterol levels.

\section{IN CONCLUSION,}

our study suggests injecting 50 microliters of $6 \%$ ascorbic acid reduced embryonic mortality and improvd hatchability and hatched chicks'body weight. 
Badran, A.M. ${ }^{1}$ et al.

Table (1): The effect of pre-incubation in ovo injection of ascorbic acid on hatchability, hatchability of fertile eggs, embryonic mortalities percentage and hatched chicks' body weight

\begin{tabular}{|c|c|c|c|c|}
\hline Treatments & $\begin{array}{c}\text { Hatchability } \\
(\%)\end{array}$ & $\begin{array}{c}\text { hatchability } \\
\text { of fertile eggs }\end{array}$ & $\begin{array}{c}\text { Embryonic } \\
\text { Mortalities } \\
(\%)\end{array}$ & $\begin{array}{c}\text { hatched } \\
\text { chicks' body } \\
\text { weight (g) }\end{array}$ \\
\hline Control & $85.7^{\mathrm{d}}$ & $83.55^{\mathrm{d}}$ & $14.3^{\mathrm{a}}$ & $39.19^{\mathrm{b}}$ \\
Ascorbic acid (2\%) & $89.7^{\mathrm{c}}$ & $86.73^{\mathrm{c}}$ & $10.3^{\mathrm{b}}$ & $38.23^{\mathrm{b}}$ \\
Ascorbic acid (4\%) & $92.1^{\mathrm{b}}$ & $88.82^{\mathrm{b}}$ & $7.9^{\mathrm{c}}$ & $40.01^{\mathrm{b}}$ \\
Ascorbic acid (6\%) & $94.8^{\mathrm{a}}$ & $91.28^{\mathrm{a}}$ & $5.2^{\mathrm{d}}$ & $46.32^{\mathrm{a}}$ \\
SEM & $0.05^{*}$ & $0.03^{*}$ & $0.001^{*}$ & $0.21^{*}$ \\
\hline
\end{tabular}

Values are means \pm standard error of the mean (SEM)

*Significant. $\quad \mathrm{N}=5$ per replicate $(15$ per treatment $)$

Table (2): The effect of pre-incubation in-ovo injection of ascorbic acid on some blood hematological parameters of day old chicks.

\begin{tabular}{|c|c|c|c|c|}
\hline Treatments & HCT(\%) & HGB(g/dL) & RBC(10\%/mm $\left.{ }^{\mathbf{3}}\right)$ & MCV $(\boldsymbol{\mu m 3})$ \\
\hline Control & 33.05 & $12.09^{\mathrm{c}}$ & 2.74 & 120.62 \\
Ascorbic acid (2\%) & 29.17 & $12.22^{\mathrm{c}}$ & 2.41 & 121.04 \\
Ascorbic acid (4\%) & 28.64 & $13.93^{\mathrm{b}}$ & 2.46 & 116.42 \\
Ascorbic acid (6\%) & 32.85 & $15.73^{\mathrm{a}}$ & 2.64 & 124.43 \\
SEM & 0.04 & $0.01^{*}$ & 0.001 & 0.12 \\
\hline
\end{tabular}

Values are means \pm standard error of the mean (SEM).

* Significant.

(HGB) Hemoglobin

(RBC) Red blood cell counts
$\mathrm{N}=5$ per replicate (15 per treatment).

(HCT) Hematocrit

(MCV) Mean corpuscular value

Table(3): The effect of pre-incubation in-ovo injection of ascorbic acid on serum cholesterol, glucose and triiodothyronin concentrations.

\begin{tabular}{|c|c|c|c|}
\hline Treatments & $\begin{array}{c}\text { Cholesterol } \\
(\mathbf{m m} / \mathbf{m o l})\end{array}$ & $\begin{array}{c}\text { Glucose } \\
(\mathbf{m g} / \mathbf{d l})\end{array}$ & $\begin{array}{c}\mathbf{T}_{\mathbf{3}} \\
(\boldsymbol{\mu} / \mathbf{L})\end{array}$ \\
\hline Control & 9.18 & $167.22^{\mathrm{c}}$ & $98.8^{\mathrm{c}}$ \\
Ascorbic acid (2\%) & 8.47 & $169.18^{\mathrm{c}}$ & $101.22^{\mathrm{c}}$ \\
Ascorbic acid (4\%) & 8.77 & $172.29^{\mathrm{b}}$ & $112.44^{\mathrm{b}}$ \\
Ascorbic acid (6\%) & 9.05 & $183.01^{\mathrm{a}}$ & $128.93^{\mathrm{a}}$ \\
SEM & 0.14 & $2.44^{*}$ & $6.55^{*}$ \\
\hline
\end{tabular}

Values are means \pm standard error of the mean (SEM)

* Significant. $\quad \mathrm{N}=5$ per replicate (15 per treatment).

$\left(\mathrm{T}_{3}\right)$ Triiodothyronin hormone 


\section{REFRENCES}

Ajakaiye, J. J.; Perez-Bello, A.; and Mollineda-Trujillo, A., 2010. Impact of VitaminsC and E Dietary Supplementation on Leukocyte Profile of Layer Hens Exposed to High Ambient Temperature and Humidity. ActaVeterinaire Brno. 79(3): 377-383.

Awad, A. L.; and Abd El-Halim, H. A. H., 2015. Effect of dipping hatching eggs in ascorbic acid solutions on some hatching traits and chick quality for local sinai chickens. Egypt. J. Poult. Sci., 35(1): 331-347.

Al-Murrani, W. K., 1982. Effect of injecting amino acids into the egg on Embryonic and subsequent growth in the domestic fowl. Brit. Poult. Sci., 23: 171-174.

Bhanja, S. K.;Mandal, A. B.; Agarwal, S. K.; Majumdar, S.; and Bhattacharyya, A., 2007. Effect of in ovo injection of vitamins on the chick weight and post-hatch growth performance in broiler chickens. World Poultry Science Association, Proceedings of the 16th European Symposium on Poultry Nutrition, France.

Burley, R. W.; and Vadehra, D. V., 1989. The eggshell and shell membranes: properties and synthesis. The avian egg: chemistry and biology, pp. 25-64. (New York, john Wiley).

Campbell, T. W. Hematology. In: Ritchie, B. W.; Harrison, G. J.; and Harrison, L. R., 1994. Avian Medicine: Principles and application. Fort Worth- FL: Wingers Publishing, pp:177-198.

Duncan, D. B., 1955. Multiple ranges and multiple $\mathrm{F}$ test. Biometrics, 11: 1.

EL-Sheikh, S. E. M.; and Salama, A. A., 2010. Effects of Vitamin $C$ and $E$ as Water Additives on Production
Performance and Egg Quality of Heat stressed Local Laying Hens in SiwaOasis. Egypt. J. Poult. Sci., 30 (3): 679-697.

Ghonim, A. I. A.; Awad, A. L.; ElShhat, A. M.; Fatouh, M. H. A. and Ali, Kh. A. A., 2008. Effect of dipping and spraying hatching eggs of Muscovy duck by ascorbic acid solutions during incubation period on hatchability traits. Egypt. J. Poult. Sci., 28: 283-298.

Ghonim, A. I. A.; Awad, A. L.; Fattouh, M. H. A. and El-Shhat, A. M., 2009. Comparative study of ascorbic acid treatment methods on hatchability traits and growth performance of ducklings. Egypt. J. Poult. Sci., 29: 1085-1099.

Harmon, I.W. 1936. Hemoglobin regulation in chickens. Poultry Science. 15: 53-6

Ipek, A.; Sahan, U. and Ylmaz, B., 2004. The effect of in ovo ascorbic acid and glucose injection in broiler breeder eggs on hatchability and chick weight. ArchiveswurGeflügelk, 68: 132-135.

Jochemsen, P. and Jeurissen, S. H. M., 2002. The localization and uptake of in ovo injected soluble and particulate substances in chickens. Poult. Sci., 81: 1811-1817.

Kutlu, H. R., 2001. Influence of wet feeding and supplementation with ascorbic acid on performance and carcass composition of broiler chicks exposed to a high ambient temperature. Archives of Animal Nutrition, 54: 127-139.

Lohakare, J. D.; Ryu, M. H.; Hahn, T. W.; Lee, J. K. and Chae, B. J., 2005. Effects of supplemental ascorbic acid on performance and immunity of 
In-ovo injection, ascorbic acid, hatchability, embryo mortalities, blood parameters

commercial broilers. Journal Applied Poultry Research, 14: 10-19.

Lucas, A. M. and Jamroz, G., 1961. "Atlas of avian hematology." U.S. Dpartment of agriculture, Monograph 25.

Meir, M. A. Ar. and Nir, A., 1984. Princubation dipping of turkey eggs. Does it affect eggshell conductance. Poult. Sci., 63: 2475-2478.

Mohammed, K. A.; El-Boghdady, A.; Soliman, M. A. H.; Abd Al-Galil, M. A. and Abd Al- Aleem, N. M., 2011. The effect of both pre-incubation dipping eggs in vitamin $\mathrm{C}$ and cooling eggs during incubation period on embryonic and hatchability parameters in two local chicken strains. Egypt. J. Poult. Sci., 31(2): 379-392.

Mohiti, A. M.; Hosseini, M., Lot, S. A.; Follahian, H. and Shariatmadar, F., 2007. Effect of Probiotics, Yeast, Vitamin E and Vitamin C Supplements on Performance and Immune Response of Laying Hen During High Environmental Temperature. International Journal of Poultry Science, 6 (12): 895-900.

Moura, L. C. and Pedroso, M. A., 2003. Anemia ferroprivanagestação.Revista de Enfermagem da Unisa, 4: 70-75.

Nowaczewski, S.; Kontecka, H. and Krystianiak, S., 2012. Effect of in ovo injection of vitamin $\mathrm{C}$ during incubation on hatchability of chickens and ducks. Folia Biologica, 60: 93-97.

Ohta, Y. andKidd, M. T., 2001. Optimum site for in ovo amino acid injection in broiler breeder eggs. Poult. Sci., 80(10): 1425-1429.

Ohta, Y.; Kidd, M. T. andIshibashi, T., 2001. Embryogrowth and amino acid concentration profiles of broiler breeder eggs, embryos, and chicks after in ovo administration of amino acids. Poult. Sci., 80: 1430-1436.

Ohta, Y.; Tsushima, N.; Koide, K.; Kidd, M. T. andIshibashi, T., 1999. Effect of amino acid injection in broiler breeder eggs on embryonic growth and hatchability of chicks. Poult. Sci., 78: 1493-98.

Pardue, S. L. and Thaxton, J. P., 1986. Ascorbic acid in poultry : A review. Worlds Poult. Sci. J., 42: 107-123.

Pires, D. L.; Sgavioli, S.; Malheiros, E. B. and Boleli, I. C., 2011. Acidoascórbico in ovosobreaeclodibidade de ovos. Anais da 21 $1^{\mathrm{a}}$ Reunión de la Asociación Latinoamericana de Producción Animal - ALPA; Montevideo. Uruguai.

Rund, B., 1989. Vitamin C plays a role in immunity. Poult. Dig. 48: 44-55.

Robel, E. J., 1993. Evaluation of egg injection method of pantothenic acid in turkey eggs and effect of supplemental pantothenic acid on hatchability. Poult. Sci., 72: 1740-1745.

Robel, E. J. and Christensen, V. L., 1991. Increasing hatchability of turkey eggs by injecting eggs with pyridoxine. Brit. Poult. Sci., 32: 509513.

Sanda, M. E., 2015. Evaluation of Quality and Cholesterol Level of Eggs of Laying Hens Placed on Drinking Water Fortified with Waterleaf (TalinumTriangulare) Mucilage. American Scientific Research Journal for Engineering, Technology, and Sciences, 13(1): 81-87

SAS Institute, 2002.SAS/STAT User's Guide: Version 8.2. SAS Institute Inc., Cary, NC.

Sgavioli, S.; Borges, L. L.; Almeida, V. R. de; Thimotheo, M.; Oliveira, J. A. and Boleli, I. C., 2013. Egg 
Badran, A.M. ${ }^{1}$ et al.

injection of ascorbic acid stimulates leucocytosis and cell proliferation in the bursaoffabricius. Int. J. Poult. Sci., 12(8): 464-472.

Shafey, T. M., 2002. Eggshell conductance, embryonic growth, hatchability and embryonic mortality of broiler breeder eggs dipped into ascorbic acid solution. Brit. Poult. Sci., 43:135-140.

Shakeel, A., 2010. Effect of Supplementing Dietary Sources of N-3 Fatty acid and Vitamin A on Laying Performance, Egg Quality and Immune Response in laying hens. $\mathrm{PhD}$ Thesis, Department of Poultry Science, University of Agriculture, Faisalabad, Pakistan. pp.192.

Stadelman, W. J., 1999. The incredibly functional egg. Poult. Sci., 78: 807811.

Tag El-Din, H. T.; El-serwt, A. A.; Abou-Egla, E. H.; Hamouda, I. A. and Awad, A. L., 2004. Effect of inovo injection material in duck eggs on hatchability, embryonic mortality and ducklings performance. Egyptian J. Anim. Prod., 41: 459-69.

Tullett, S. C., 1978. Pore size versus pore number in avian eggshell, in: Piiper, J. (Ed) Respiratory function in birds, Adult and Embryonic, pp. 217-226 (Berlin, Springer-Verlag).
Tullett, S. C., 1990. Science and the art of incubation. Poultry Science. 69: 115.

Uni, Z. andFerket, R. P., 2003. Enhancement of oviparous species by in ovo feeding. US Patent 6.592.878 B2. North Carolina State University, Raleigh, NC; and Yissum Research Development Company of Hebrew University of Jerusalem, Jerusalem, 31 Jul. 2001, 15 Jul.

Zakaria, A. H. and El-Anezi, M. A., 1996. Effect of ascorbic acid and cooling during egg incubation on hatchability, culling, mortality and the body weights of broiler chickens. Poult. Sci., 75: 1204-1209.

Zakaria, A. H.; Al-latif, A. A. and AlAnezi, M. A., 1998. Effect of ascorbic acid on embryonic development, hatch time and growth of extended delayed placement of broiler chickens. Arch. Geflüg., 62(1): 11-15.

Zeidler, E., 2002. Shell eggs and their nutritional value In: Bell D.D and Weaver, W.D (eds.) Commercial chicken meat and Egg production. Kluwer Academic Publisher, New York USA. pp. 1109-1128. 


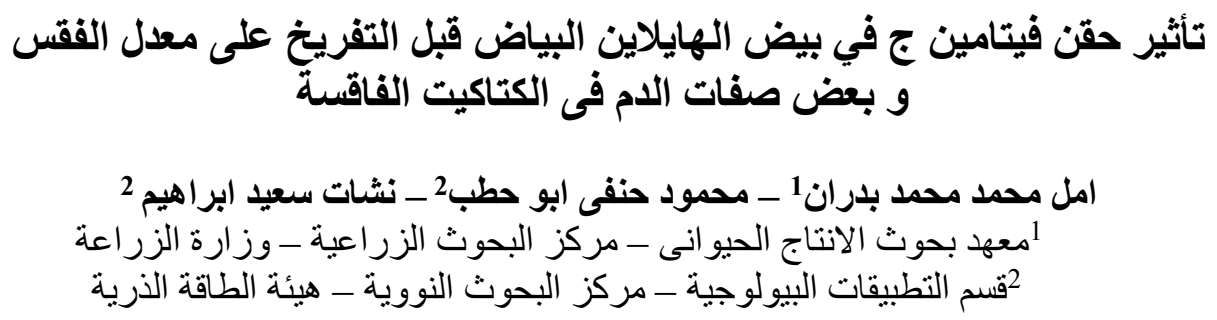

هدف هذا البحث هو در اسة تأثثر حقن بيض التفريخ لسلالة الهايلاين البياض قبل التفريخ بفيتامين ج و در اسة تأثير

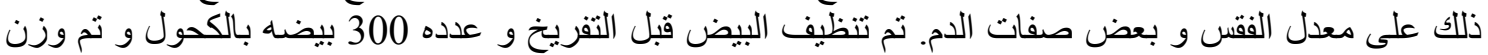

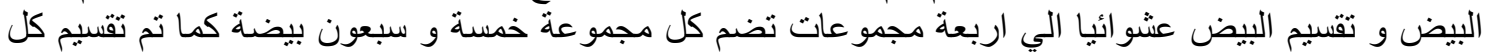

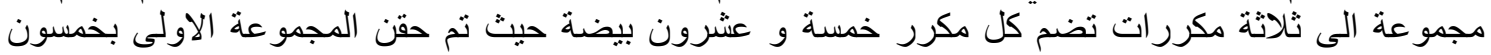

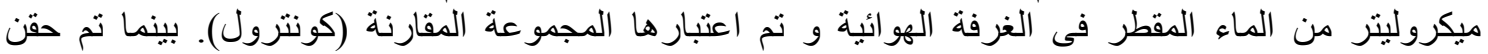

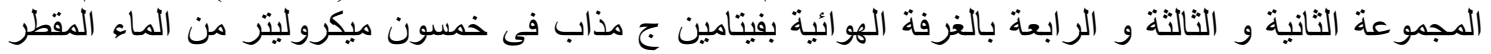

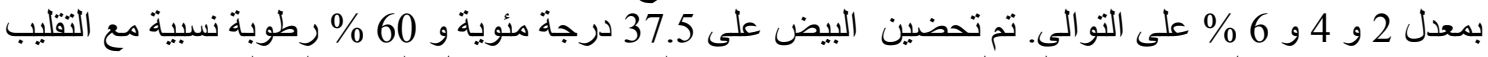

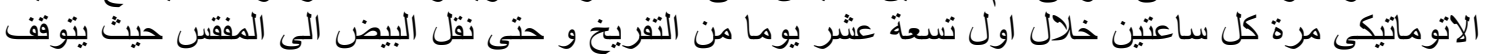

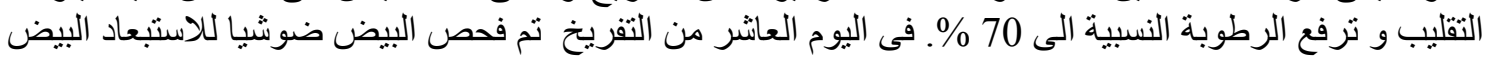

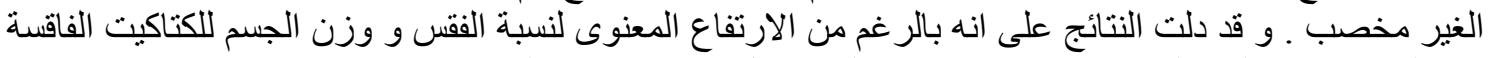

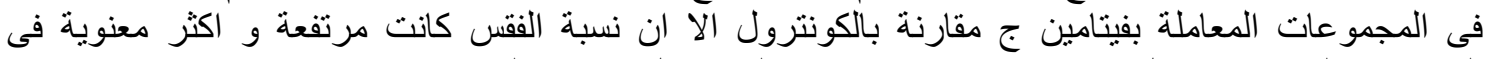

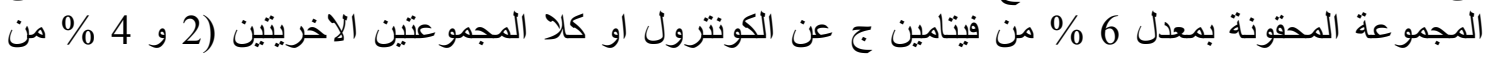

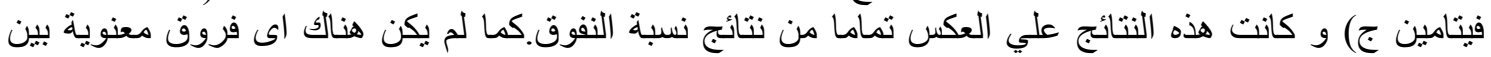

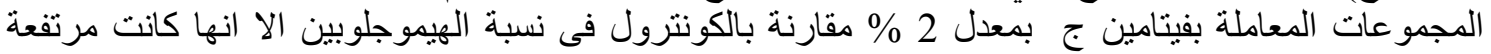

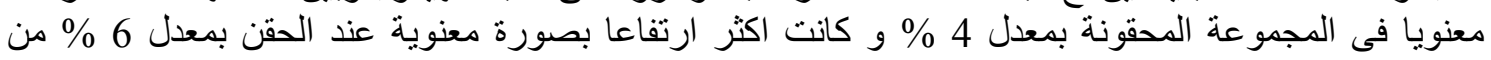

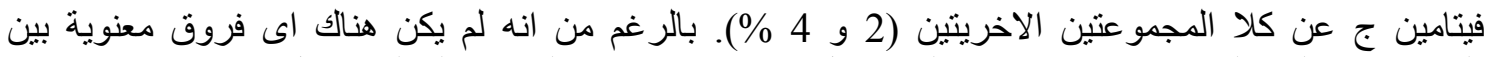

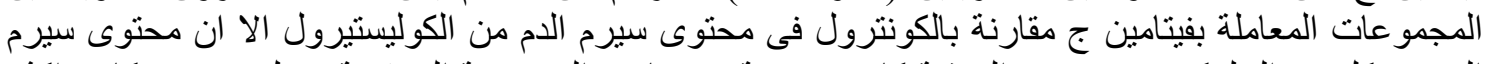

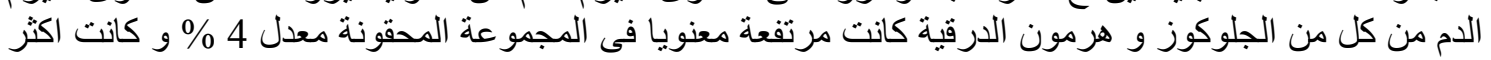

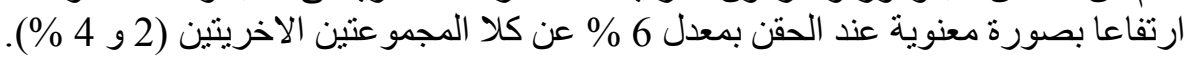

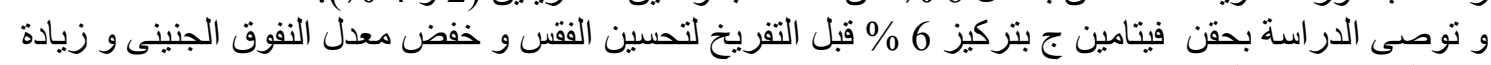
وزن الكتاكيت عند الفقس. 